\title{
FLORA DA SERRA DO CIPÓ, MINAS GERAIS: DILLENIACEAE ${ }^{1}$
}

\author{
CARLA POLESELLI BRUNIERA* \& MILTON GROPPO**
}

\author{
*Departamento de Botânica, Instituto de Biociências, Universidade de São Paulo, Rua do Matão 277, \\ Cidade Universitária, 05508-900 - São Paulo, SP, Brasil (e-mail: carla bruniera@yahoo.com.br) \\ **Departamento de Biologia, Faculdade de Filosofia, Ciências e Letras de Ribeirão Preto, Universidade de São Paulo. \\ Av. Bandeirantes, 3900 - CEP 14040-901, Ribeirão Preto, São Paulo, Brasil (e-mail: groppo@ffclrp.usp.br)
}

\begin{abstract}
Flora of Serra do Cipó, Minas Gerais: Dilleniaceae). The study of the family Dilleniaceae is a part of the project of "Flora of Serra do Cipó, Minas Gerais, Brazil". In that area, the family is represented by the genus Curatella, with one species, Davilla, with four species, and Doliocarpus, with two species. Keys to the genera and species, descriptions and illustrations, as well as comments on the geographic distribution, phenology and variability of the species are presented.

Resumo - (Flora da Serra do Cipó, Minas Gerais: Dilleniaceae). O estudo da família Dilleniaceae é parte do levantamento da Flora da Serra do Cipó, Minas Gerais, Brasil. Esta família está representada na área pelos gêneros Curatella, com uma espécie, Davilla, com quatro espécies, e Doliocarpus, com duas espécies. São apresentadas chaves para gêneros e espécies, descrições e ilustrações, além de comentários sobre distribuição geográfica, fenologia e variabilidade.
\end{abstract}

Key words: Curatella, Davilla, Doliocarpus, floristics, campo rupestre.

\section{Dilleniaceae ${ }^{2}$}

Arbustos, árvores ou lianas. Folhas alternas, simples, sem estípulas. Inflorescências terminais, axilares ou ramifloras, determinadas, geralmente paniculadas, fasciculadas ou tirsóides (Tetracera), raramente flores solitárias. Flores geralmente bissexuadas, diclamídeas; cálice (3)4-7(-14)mero, dialissépalo, persistente na frutificação, sépalas acrescentes ao fruto (Davilla), prefloração imbricada; corola (2)3-5(-7)-mera, dialipétala, geralmente alva ou amarelada e decídua, prefloração imbricada; estames numerosos, geralmente persistentes no fruto, filetes filiformes, anteras rimosas e basifixas; gineceu apocárpico, menos freqüentemente hemissincárpico, ovário súpero, 1-5(-8) carpelos, lóculos 1(-2), óvulos 1-2 por lóculo, placentação submarginal ou basal, estiletes livres entre si, estigma capitado ou peltado. Fruto folículo, baga, cápsula ou núcula (Curatella), apocárpico. Sementes 1-2 por lóculo, arilo carnoso ou delgado, inteiro ou laciniado, endosperma copioso; embrião diminuto, estreito.

Dilleniaceae possui 10-14 gêneros e ca. 500 espécies (Horn 2009), com distribuição pantropical, e algumas espécies com distribuição subtropical (Kubitzki 2004). No Neotropico são encontradas 102 espécies distribuídas nos gêneros Curatella Loefl. (1), Davilla Vand. (30), Doliocarpus Rol. (48), Neodillenia Aymard (3), Pinzona Mart. \& Zucc. (1) e Tetracera L. (17), enquanto no Brasil 81 dessas espécies se fazem presentes, 30 em Davilla, 33 em Doliocarpus, 15 em Tetracera, uma em Neodillenia, além dos gêneros monoespecíficos Curatella e Pinzona (Fraga, comunicação pessoal). Na Serra do Cipó apenas Curatella (1), Davilla (4) e Doliocarpus (2) encontram-se representados.

Bibliografia básica: Eichler (1863); Kubitzki (1970, 1971, 2004); Kubitzki \& Reitz (1971); Zmarzty (1995); Aymard (1997, 2007); Mendonça \& Sano (2003); Fraga \& Aymard (2007); Horn (2007, 2009); Fraga (2008).

\section{Chave para os gêneros}

1. Árvores; carpelos 2, unidos na base

1. Curatella

1 '. Arbustos ou lianas; carpelos 2, livres, ou carpelo 1.

2. Inflorescências terminais ou laterais no ápice dos ramos; sépalas internas 2, maiores que as externas ( 2 a 3 vezes no comprimento), acrescentes ao fruto 2. Davilla

2'. Inflorescências ramifloras; sépalas de tamanho similar 3. Doliocarpus

\footnotetext{
${ }^{1}$ Trabalho realizado segundo o planejamento apresentado em Giulietti et al. (1987).

${ }^{2}$ Descrição baseada nos gêneros presentes na região Neotropical.
} 


\section{Curatella Loeff.}

Árvores. Inflorescência paniculada. Flores bissexuadas; sépalas 3-5, semelhantes entre si; pétalas 3-5, obovais, decíduas; estames numerosos, persistentes no fruto; carpelos 2, uniloculares, soldados na base, lóculos biovulados, estiletes 2 , livres, sublaterais, estigma peltado. Fruto nucáceo, núcula dímera, com base fundida. Sementes 2 por lóculo, arilo presente, completo ou incompleto.

Curatella americana L. constitui a única espécie do gênero.

1.1. Curatella americana L., Syst. Nat. ed. 10: 1079. 1759.

Fig. 1 A-E

Árvores, 3,0-5,0 m alt.; ramos jovens tomentosos, quando velhos glabros com ritidoma descamante. Lâmina foliar 6,0-18,0 cm compr., 4,0-11,5 cm larg., coriácea, áspera, elíptica ou oval, ápice emarginado ou arredondado, base atenuada, margem denteada quando jovem e sinuosa quando adulta, face adaxial esparsamente flocosa, face abaxial densamente flocosa, nervuras laterais 10-19, mais evidentes na face abaxial; pecíolo 1,0-2,0 cm compr., alado, tomentoso. Panícula até $8,0 \mathrm{~cm}$ compr., tomentosa. Sépalas 5,0-7,0 mm compr., elípticas, pilosas em ambas as faces; pétalas 7,0-9,0 $\mathrm{mm}$ compr., obovais, glabras; estames $60-80,5,0-7,0 \mathrm{~mm}$ compr.; ovário 1,0-2,0 mm compr., densamente pubescente, estilete 2,0-3,0 mm compr., glabro. Núcula 4,0-6,0 $\mathrm{mm}$ compr., elipsóide, densamente pubescente. Semente 3,0-4,0 mm compr., elipsóide a oboval.

Material examinado: Minas Gerais, Jaboticatubas, Serra do Cipó, trilha para a Cachoeira da Farofa, próximo à Sede do IBAMA,
19²2'26,0”S, 4335'52,9”W, 802 m s.n.m., 22.IX.2007, C.P. Bruniera et al. 65, fl. fr. (CEPEC, ESA, K, RB, SPF, SPFR); idem, C.P. Bruniera et al. 66, fl. fr. (SPFR); Santana do Riacho, Serra do Cipó, UCAT, 23.II.1985, M.A. Lopes \& P.M. Andrade s.n., estéril (BHCB); idem, Lagoa Comprida, caminho para a Cachoeira da Farofa, 7.IX.1987, M.G.L. Wanderley et al. s.n. CFSC 10607, fl. fr. (SPF, SPFR).

Curatella americana ocorre desde a América Central até a Bolívia e em quase todo o Brasil (limite meridional em São Paulo). Está associada principalmente a formações abertas, como cerrado (Kubitzki 1971), em todas as suas fisionomias, sendo uma das espécies típicas deste tipo de vegetação. $\mathrm{Na}$ Serra do Cipó a espécie ocupa os ambientes de cerrado, com flores e frutos em setembro. O caule descamante e as folhas ásperas ao toque facilitam a identificação no campo.

\section{Davilla Vand.}

Arbustos ou lianas. Inflorescência em panículas terminais ou em ramos laterais. Flores bissexuadas; sépalas 5, livres, desiguais, as 3 externas menores, as 2 internas maiores ( 2 a 3 vezes no comprimento), acrescentes ao fruto; pétalas 3-6, livres, decíduas, freqüentemente ovais; estames numerosos, persistentes no fruto; carpelos 1 ou 2, livres, uniloculares, lóculos 1-ovulados, estiletes sublaterais, estigma peltado. Frutos capsulares, pericarpo membranáceo, deiscente pela sutura ou fendidos irregularmente, sépalas internas acrescentes, espessadas e endurecidas, envolvendo o fruto. Sementes 1 ou 2, arilo incluso completo.

O gênero Davilla possui ca. 30 espécies (Fraga 2008), que se distribuem desde o sul do México até o sul do Brasil (Santa Catarina), Bolívia e Paraguai (Horn 2007). Na Serra do Cipó, ocorrem quatro espécies.

\section{Chave para as espécies}

1. Margens das sépalas internas pressionadas entre si, formando alas circulares

2.1. D. angustifolia

1'. Margens das sépalas internas sobrepostas, não formando alas.

2. Lianas; carpelo 1

2.4. D. nitida

2'. Arbustos, ou subarbustos, raramente arbusto escandente; carpelos 2.

3. Folhas com face abaxial serícea-tomentosa nas nervuras e pubescente-estrigosa no restante da lâmina; sépalas densamente seríceas externamente 2.2. D. elliptica

3'. Folhas com face abaxial serícea-estrigosa nas nervuras e estrigosa a glabra no restante da lâmina; sépalas glabras externamente ou com tricomas esparsos 2.3. D. grandiflora

\subsection{Davilla angustifolia A.St.-Hil., Fl. Bras. Mer. 1:} 19. 1825.

Fig. 1 F-H

Liana ou arbusto escandente; ramos jovens seríceos, quando velhos glabros e descamantes. Lâmina foliar 5,0$20,0 \mathrm{~cm}$ compr., 1,5-5,0 cm larg., coriácea, lanceolada ou estreitamente elíptica, raramente elíptica, ápice agudo ou acuminado, base obtusa ou arredondada, margem inteira ou levemente serreada na metade anterior, face adaxial glabra, face abaxial com nervuras central e laterais seríceas, nervuras laterais 10-16; pecíolo 0,8-2,0 cm compr., estreitamente aladorecurvado, seríceo. Panícula 3,5-16,0 cm compr., ferrugíneotomentosa. Sépalas largamente ovais ou circulares, seríceas externamente, as externas $0,3-0,4 \mathrm{~cm}$ compr., as internas 0,8 1,0(-1,3 após a antese) $\mathrm{cm}$ compr., margem das sépalas internas pressionadas entre si, formando alas circulares; pétalas 3, 0,8$1,0 \mathrm{~cm}$ compr., obcordadas, glabras; estames $80-100,3,0-4,0$ 
mm compr.; carpelos 2, glabros, ovário ca. 2,0 mm compr., estilete ca. 4,0 mm compr. Cápsulas 2, 1-semente por cápsula. Semente 5,0-8,0 mm compr., elipsóide ou oboval.

Material examinado: Minas Gerais, Serra do Cipó, 10-20 km a nordeste de Cardeal Mota, caminho a Conceição do Mato Dentro, 19²0'S, 4335' 'W, 15.V.1990, M.M. Arbo et al. 4123, fr. (SPF, SPFR); Conceição do Mato Dentro, Parque Natural Municipal do Ribeirão do Campo, 1905’30,6”S, 4334'10,8”W, 23.IV.2003, R.C. Mota 2081, fl. (BHCB); Santana do Riacho, Serra do Cipó, 7.IX.1980, F. de Barros 359, fr. (SP, SPFR); idem, 24.IX.1993, J.A. Lombardi \& F.R.N. Toledo 439, fr. (BHCB); idem, Alto do Palácio, Próximo à Estátua do Juquinha, 2.V.1993, V.C. Souza \& C.M. Sakuragui 3440, fl. fr. (ESA); idem, ao longo da MG-010, $19^{\circ} 16^{\prime} 38,8^{\prime}$ 'S, $43^{\circ} 32^{\prime} 56,9^{\prime} \mathrm{W}, 1164 \mathrm{~m}$ s.n.m., 16.VI.2007, C.P. Bruniera et al. 36, fr. (CEPEC, ESA, K, SPF, SPFR); idem, C.P. Bruniera et al. 38, fr. (RB, SPF, SPFR); idem, MG-010, ca. $400 \mathrm{~m}$ antes da bifurcação Morro do Pilar/Conceição do Mato Dentro, $19^{\circ} 12^{\prime} 53,8^{\prime \prime S}, 43^{\circ} 30 ’ 39,0$ ”W, 1349 m s.m.m., 14.VI.2007, C.P. Bruniera et al. 17, fr. (K, RB, SPF, SPFR); idem, 8.VIII.1993, M.T.V.A. Campos \& N. Roque s.n. CFSC 13329, fr. (SP, SPF); idem, 20.XI.1993, M.T.V.A. Campos \& E.D.P. Souza s.n. CFSC 13514, fr. (SPF); idem, Rodovia MG-010, km 107, caminho para a Usina Dr. Pacífico Mascarenhas, 7.IX.1980, E. Forero et al. 8062 CFSC 8975, fr. (SP, SPF, SPFR); idem, km 112, Córrego 2 Pontinhas, 5.IV.1995, M. Sztutman et al. s.n. CFSC 13864, fl. (SPF, SPFR); idem, km 117, 7.VII.1974, I. Sazima s.n. CFSC 5065, fr. (SP); idem, km 126, 10-15.XII.1973, J. Semir \& D.A. Lima s.n. CFSC 4817, fr. (SP); idem, km 129, 19.IV.1950, A.P. Duarte 2745, estéril (RB)

Material adicional examinado: Bahia, Serra do Sincorá, $13^{\circ} 35^{\prime}$ 'S, $41^{\circ} 27^{\prime}$ W, 1300 m s.n.m., 22.III.1980, Harley et al. 20707, fl. (SPF).

Segundo Kubitzki (1971), a espécie é conhecida a partir de coletas no estado de Minas Gerais, no entanto sua distribuição provavelmente é mais ampla, abrangendo outros estados, como a Bahia (col. Harley et al. 20707, material adicional examinado). $\mathrm{Na}$ Serra do Cipó, foi coletada em campos rupestres, cerrado, capões de mata e matas de galeria. Coletada com flores em abril e maio, e com frutos de maio a dezembro.

\subsection{Davilla elliptica A.St.-Hil., Fl. Bras. Mer. 1: 13. 1825.} Fig. 1 I-M

Arbusto ou subarbusto ereto, 0,3-2,3 m alt., raramente arbusto escandente; ramos tomentosos, tricomas douradoamarronzados, quando velhos glabros e descamantes. Lâmina foliar 4,0-14,0 cm compr., 2,2-9,5 cm larg., coriácea, áspera, oblonga, elíptica, largamente ou estreitamente elíptica, ápice arredondado, agudo ou acuminado, raramente emarginado, base arredondada ou obtusa, margem inteira ou sinuososerreada, face adaxial glabra ou com tricomas espaçados na nervura central, face abaxial seríceo-tomentosa na nervura central e laterais e pubescente-estrigosa no restante da lâmina, raramente glabra, nervuras laterais 8-17, proeminentes na face abaxial; pecíolo $0,7-2,0 \mathrm{~cm}$ compr., estreitamente alado-recurvado, tomentoso. Panícula 5,5-20,0 cm compr., pubescente-tomentosa. Sépalas densamente seríceas externamente, externas 0,3-0,5 cm compr., largamente ovais, internas $0,6-1,0(-1,2$ após a antese) $\mathrm{cm}$ compr., oboval ou circular, margens sobrepostas não formando alas; pétalas 5 , 0,5-0,8 cm compr., obovais ou oblanceoladas, comumente com ápice emarginado, glabras; estames ca. 90, 3,0-5,0 $\mathrm{mm}$ compr.; carpelos 2 , glabros, ovário 1,0-2,0 mm compr., estilete 3,0-5,0 mm compr. Cápsulas 2,1-semente por cápsula. Semente ca. 5,0 mm compr., largamente oblonga.

Material examinado: Minas Gerais, Jaboticatubas, Serra do Cipó, 26.VII.1979, W. Mantovani 122, fl. fr. (SP, SPFR); idem, Estrada da Usina, 21.V.1974, J. Semir \& A.M. Giulietti s.n. CFSC 5019, bot. (SP); idem, Estrada da Usina, a $10 \mathrm{~km}$ da Pensão Chapéu de Sol, 16.IV.1972, A.B. Joly et al. s.n. CFSC 1703, bot. fr. (SP); idem, trilha da Sede do IBAMA, 19²0'56,2”S, 4337’03,1”W, 1198 m s.n.m., 15.VI.2007, C.P. Bruniera et al. 21, fl. fr. (SPFR); idem, C.P. Bruniera et al. 22, fr. (SPF, SPFR); idem, C.P. Bruniera et al. 23, fl. fr. (K, RB, SPF, SPFR); idem, C.P. Bruniera et al. 24, fl. (CEPEC, RB, SPF, SPFR); idem, C.P. Bruniera et al. 25, bot. fl. fr. (ESA, K, RB, SPF, SPFR); idem, São José de Almeida, 26.II.2001, A.F. Silva 61, fl. (BHCB). Santana do Riacho, Véu da Noiva, 2.V.1986, T.B. Cavalcanti et al. s.n. CFSC 9685, bot. fl. (SPF, SPFR); Estrada dos Escravos, próximo à Cachoeira, 13.VIII.2005, D.D. Abreu et al. 12, fr. (SPF); estrada entre a Sede do IBAMA e a Cachoeira da Farofa, ca. 2,5 km da Sede, 19²2'10"'S, 43³6'03”W, 950 m s.n.m., 4.VII.2001, V.C. Souza et al. 25009, fr. (ESA); MG-010, km 87,5, 18.VII.1983, J. Diacui \& G. Esteves s.n. CFSC 9138, fr. (RB, SPF, SPFR); idem, km 89, 10.IV.1995, M. Stutzman et al. s.n. CFSC 13975, fl. (SPF); idem, km 101, 14.XII.1984, G.L. Esteves et al. s.n. CFCR 5931, fr. (SPF); idem, km 104, 7.X.1981, M.L. Kawasaki et al. s.n. CFSC 7558, fr. (SPF); idem, km 105, Pensão Chapéu do Sol, 1.V.1982, I. Cordeiro s.n. CFSC 8281, fl. (SPF, SPFR), idem, km 105, Vale da Mãe d'Água, 1.VIII.1982, J.D.P. de Oliveira \& G.L. Esteves s.n. CFSC 8592 , bot. fr. (RB, SPF, SPFR); idem, estrada em direção à Cachoeira da Caverna, 19¹4'46,5”'S, 43³5'00,2”W, 1010 m s.n.m., 23.IX.2007, C.P. Bruniera et al. 73, bot. fr. (ESA, K, RB, SPF, SPFR); idem, idem, $19^{\circ} 15^{\prime} 09,9^{\prime \prime} \mathrm{S}, 43^{\circ} 35^{\prime} 07,1^{\prime \prime} \mathrm{W}, 1062$ m s.n.m., 23.IX.2007, C.P. Bruniera et al. 77, fr. (K, RB, SPF, SPFR); idem, arredores do Córrego Chapéu de Sol, 4.VII.1996, V.C. Souza et al. 11673, bot. fl. fr. (ESA); idem, próximo à Pensão Chapéu de Sol, 5.VII.2001, V.C. Souza et al. 25070, fr. (ESA); idem, $18 \mathrm{~km}$ acima do Chapéu de Sol, ca. $1370 \mathrm{~m}$ s.n.m., 4.VI.1976, G. Martinelli 869, fl. fr. (RB); idem, UCAT, 15.IV.1985, P.M. Andrade \& M.A. Lopes s.n., fl. (BHCB); idem, Fazenda Paraúna, em direção à Lapinha, $19^{\circ} 10^{\prime} \mathrm{S}, 43^{\circ} 42^{\prime} \mathrm{W}, 1360$ m s.n.m., 23.XI.2000, L.S. Kinoshita \& M.E. Alencar 00/422, fr. (UEC); idem, distrito de Cardeal Mota, sede da Fazenda Monjolos, 24.IX.2002, K. Yamamoto \& L.S. Kinoshita 02/72, fr. (UEC). Santana do Pirapama, Fazenda Inhame (Serra Mineira), $1^{\circ} 55^{\prime}$ 'S, 435'' W, 20.III.1982, J.R. Pirani et al. s.n. CFSC 7975, bot. (SPF, SPFR). Serra do Cipó, 1978, A.B. Martins s.n., fr. (BHCB).

Davilla elliptica ocorre na Bolívia e no Brasil, com coletas na Bahia, Goiás, Minas Gerais, Mato Grosso e São Paulo (Kubitzki 1971, Mendonça \& Sano 2003). Segundo Kubitzki (1971), a espécie ocorre no cerrado, preferencialmente como arbustos de baixo porte, raramente como arvoretas ou arbustos escandentes. 


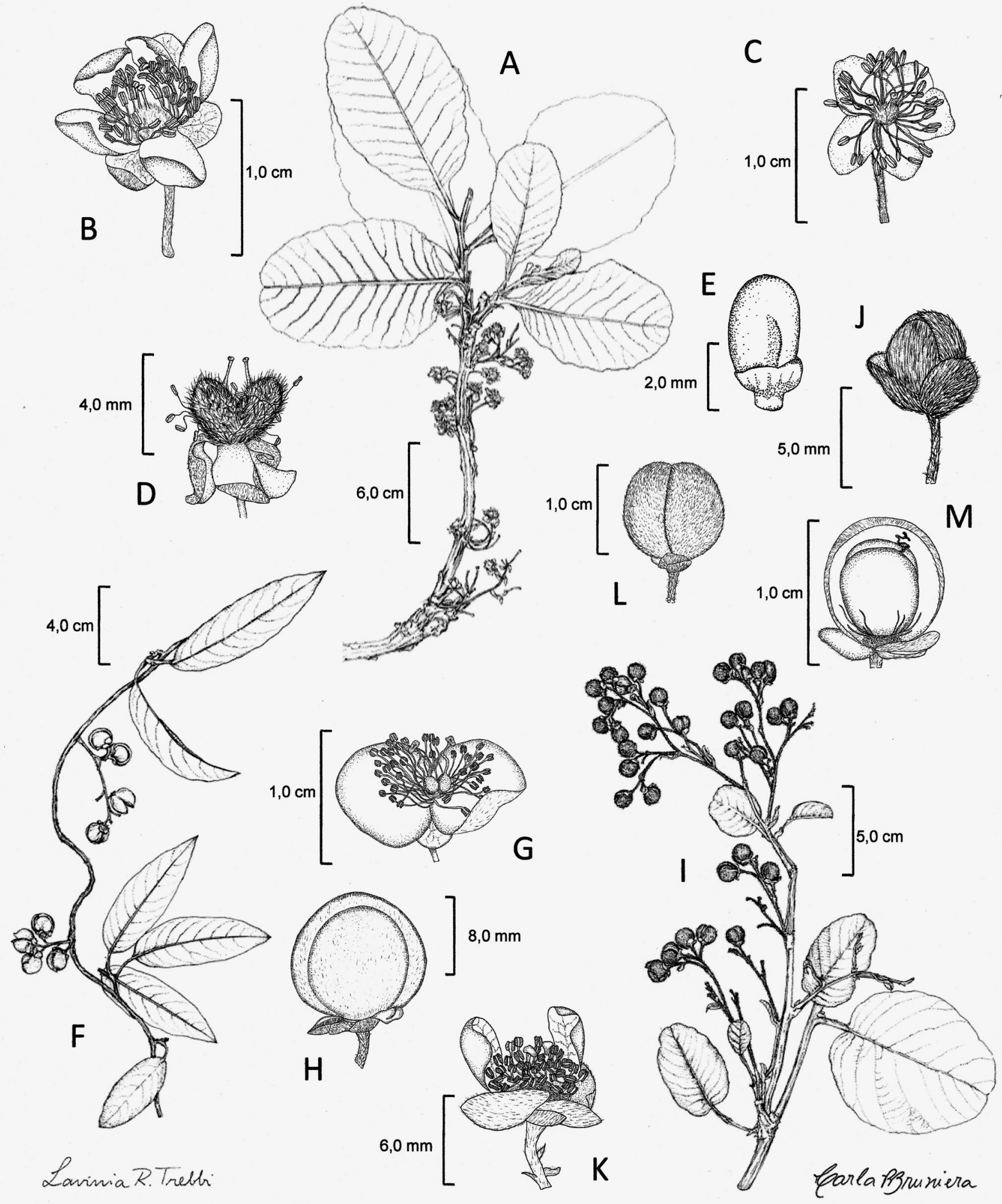

Fig. 1. A-E. Curatella americana L. A. Ramo com frutos. B. Botão aberto. C. Flor com pétalas ausentes. D. Fruto, notar cálice e estames persistentes. E. Semente em vista lateral, notar arilo incompleto. F-G. Davilla angustifolia A.St.-Hil. F. Ramo com frutos. G. Flor com pétalas ausentes. H. Fruto envolvido pelas sépalas internas acrescentes. I-M. Davilla elliptica A.St.-Hil. I. Ramo com frutos. J. Botão. K. Flor com algumas pétalas retiradas. L. Fruto envolvido pelas sépalas internas acrescentes. M. Frutos com uma das sépalas internas retirada. (A. Bruniera et al. 65; B, D. Bruniera et al. 66; C. Kawasaki et al. 8260; E. Kinoshita et al. C-071; F. Arbo et al. 4123; G. Mota 2081; H. Bruniera et al. 17; I. Bruniera et al. 73; J. Semir \& Giulietti CFSC 5019; K. Cavalcanti et al. CFSC 9685; M. Martins s.n. BHCB 3533) 
Na Serra do Cipó, a espécie foi encontrada em ambientes de cerrado, campo rupestre e matas de galeria. Floresce e frutifica provavelmente o ano todo (Mendonça \& Sano 2003), sendo que os materiais da Serra do Cipó com flores datam de fevereiro a setembro, e os materiais com frutos de fevereiro a dezembro. Davilla elliptica se assemelha bastante com $D$. grandiflora A.St.-Hil. \& Tul., que também ocorre na Serra do Cipó, pois ambas são espécies de hábito arbustivo ou subarbustivo, com características vegetativas e reprodutivas muito semelhantes. A principal diferença entre elas está no indumento da lâmina foliar e das sépalas. $D$. elliptica possui a face abaxial da lâmina foliar seríceo-tomentosa nas nervuras e pubescente-estrigosa no restante da lâmina, enquanto que em $D$. grandiflora a face abaxial é seríceo-estrigosa nas nervuras e estrigosa a glabra no restante da lâmina. Em relação às sépalas, $D$. elliptica apresenta as sépalas densamente seríceas externamente, mesmo no período de frutificação (ver Fig. 1L), sendo que D. grandiflora possui sépalas glabras externamente ou com tricomas esparsos, glabrescentes na frutificação (ver Fig. 2C).

2.3. Davilla grandiflora A.St.-Hil. \& Tul., Ann. Sci. Nat., Bot. sér. 2, 17: 131. 1842.

Fig. 2 A-D

Arbusto ou subarbusto até 2,0(3,0) $\mathrm{m}$ alt.; ramos esparsamente estrigosos ou glabros, quando velhos acinzentados e descamantes. Lâmina foliar 3,0-11,5 cm compr., 2,0-5,5 cm larg., coriácea, áspera, elíptica ou estreitamente elíptica, raramente oval ou oblonga, ápice arredondado ou acuminado, raramente agudo, base arredondada ou obtusa, margem inteira ou sinuoso-serreada, face adaxial glabra, face abaxial serícea-estrigosa nas nervuras e no restante da lâmina estrigosa a glabra, nervuras laterais 8-10(-15), proeminentes na face abaxial; pecíolo $0,5-1,5 \mathrm{~cm}$ compr., estreitamente alado, glabro ou seríceo. Panícula 4,5-15,0 cm compr., estrigosa a glabra. Sépalas glabras externamente ou com tricomas esparsos, margem ciliada, externas $0,3-0,6 \mathrm{~cm}$ compr., largamente ovais ou circulares, internas 0,7-0,9(-1,5 após a antese) cm compr., circulares, margens sobrepostas não formando alas; pétalas 3-5, 0,7-1,2 cm compr., estreitamente obcordadas, glabras; estames 80-110, 4,0-5,0 mm compr.; carpelos 2, glabros, ovário ca. 1,0 $\mathrm{mm}$ compr., estilete 4,0-5,0 $\mathrm{mm}$ compr. Cápsulas 2, 1-semente por cápsula. Semente ca. 5,0 mm compr., largamente oblonga.

Material examinado: Minas Gerais, Jaboticatubas, Serra do Cipó, Rodovia Belo Horizonte - Conceição do Mato Dentro, km 112, 5.III.1972, A.B. Joly et al. s.n. CFSC 1025, fl. (SP); idem, km 112,5, 1020 m s.n.m., 15.IV.1972, A.B. Joly et al. s.n. CFSC 1447, fl. fr. (SP); idem, km 113, 1080 m s.n.m., 15.IV.1972, A.B. Joly et al. s.n. CFSC 1509, fl. (SP); idem, km 114, 5.VI.1970, A.B. Joly et al. s.n. CFSC 47, fr. (SP); idem, km 114, 29.V.1972, A.B. Joly et al. s.n. CFSC 2552, fl. (SP); idem, km 114, 8.IX.1972, A.B. Joly \& C. Müller s.n. CFSC 3428, fr. (SP); idem, km 116, 1175 m s.n.m., 6.VI.1970, A.B. Joly et al. s.n. CFSC 83, fl. fr. (SP); idem, km 118, 4.III.1972, A.B. Joly et al. s.n. CFSC 971, fl. fr. (SP); idem, km 118, 3.XI.1972, A.B. Joly \& J. Semir s.n. CFSC 3541, fl. (SP). Santana do Riacho, Serra do Cipó, 20.X.1990,
J.R. Stehmann et al. s.n., fr. (BHCB); idem, ca. $1400 \mathrm{~m}$ s.n.m., 11.V.1974, G. Martinelli 298, fl. (RB); idem, 19¹7'15”'S, 4335'20”W, 1100-1200 m s.n.m., 11.VII.1998, J.R. Stehmann \& E. Franceschinelli 2364, fl. fr. (BHCB); idem, estrada para Lapinha, $4 \mathrm{~km}$ da cidade, 1000 m s.n.m., 18.II.1982, C.F. Muniz et al. s.n. CFSC 7896, fl. fr. (SPF); idem, Estrada Santana do Riacho - Lapinha, $19^{\circ} 08^{\prime} \mathrm{S}, 43^{\circ} 41^{\prime} \mathrm{W}, 1150 \mathrm{~m}$ s.n.m., 5.III.1998, R.C. Forzza et al. 762, fl. (SPF, SPFR); idem, Rodovia Belo Horizonte - Conceição do Mato Dentro, ca. $2 \mathrm{~km}$ acima da estrada da Usina, 11.I.2006, A.P. Savassi-Coutinho et al. 937, fl. (ESA); idem, ca. 1,5 km da Pousada Chapéu do Sol, 30.IV.1989, L.C. Giordano \& A. Toscano 666, fl. (RB); idem, Estrada da Usina Dr. Pacífico Mascarenhas, 5.X.1981, A. Furlan et al. s.n. CFSC 7510, fr. (SPF, SPFR); idem, Estrada da usina até $10 \mathrm{~km}$ da entrada, 18.VII.1983, J. Diacui \& G. Esteves s.n. CFSC 9137, fr. (SPF); idem, Estrada da Usina, 4 km da Pensão Chapéu do Sol, 24.X.1982, J. Diacui et al. s.n. CFSC 9074, bot. fl. fr. (RB, SPF, SPFR); idem, Estrada da Usina, 24.X.1982, J. Diacui et al. s.n. CFSC 9080, bot. (SPF, SPFR); idem, Estrada da Usina, Fazenda do Sr. Cornélio, 24.X.1982, J. Diacui et al. s.n. CFSC 9075, fl. fr. (RB, SPF, SPFR); idem, entre Córrego Vitalino e estrada da Usina, 7.IV.1995, $M$. Sztutman et al. s.n. CFSC 13917, fl. (SPF); idem, Estrada para a Usina Pacífico Mascarenhas, 19¹6’22,6”S, 43³6’09,9”'W, 1005 m s.n.m., 23.IX.2007, C.P. Bruniera et al. 67, 69, 71 e 72, fr. (SPF, SPFR); idem, C.P. Bruniera et al. 72, fr. (SPFR), idem, MG-010, km 101, 16.VII.1983, G.L. Esteves \& J. Diacui s.n. CFSC 9124, fl. (SPF, SPFR); idem, km 103, Estrada da Usina, $10 \mathrm{~km}$ da entrada, 19.III.1983, M.L. Kawasaki et al. s.n. CFSC 9103, fr. (SPF, SPFR); idem, km 103-104, ca. $1100 \mathrm{~m}$ s.n.m., 26.IV.1978, H.C. de Lima 454, fl. fr. (RB, SPFR); idem, km 106, 19²17'S, 43³6'W, V.1990, G.M. Faria \& M. Mazucato s.n., fl. (SPF); idem, km 115, 20.III.1983, M.G.L. Wanderley s.n. CFSC 9116, fr. (SPF, SPFR); idem, km 116, 8.II.1991, H.C. Souza s.n. CFSC 11869, fr. (SPF, SPFR); idem, MG-010, 5,5-6,0 km após a ponte sobre o Rio Vacaria, 19¹7'26"S, 4335'45'W, 1217 m, 24.IV.2006, R. Mello-Silva et al. 2922, fl. (SPF, SPFR). Serra do Cipó, 22.IV.1990, E. Leandro s.n., fl. (BHCB); 1060 m s.n.m., 15.III.1964, E. Pereira 8857, fl. (RB); estrada para Diamantina, ca. 1500 m s.n.m., 28.IV.1973, P.I.S. Braga \& M.F. Osnir 2651, fl. fr. (RB).

Espécie distribuída pelos estados de Goiás, Minas Gerais e Mato Grosso, além de ocorrer também na Bolívia e no Paraguai. Está presente no cerrado, crescendo tanto em solo arenoso quanto pedregoso (Kubitzki 1971). Na Serra do Cipó, é encontrada nos cerrados, em campos rupestres e matas de galeria. A espécie provavelmente floresce e frutifica o ano todo, já que os materiais com flores da Serra do Cipó datam de todos os meses do ano (com exceção de agosto, setembro e dezembro), e o mesmo ocorre com os materiais com frutos (com exceção de agosto, novembro e dezembro), sugerindo provavelmente a falta de coleta nessas datas e não uma interrupção fenológica de floração e frutificação.

2.4. Davilla nitida (Vahl) Kubitzki., Mitt. Bot. Staatssamml. München 6: 95. 1971.

Fig. 2 E-G

Lianas; ramos glabros ou esparsamente estrigosos, quando velhos descamantes. Lâmina foliar 5,5-16,0 cm compr., 
2,5-9,5 cm larg., coriácea, elíptica, ápice arredondado ou agudo, base arredondada ou obtusa, margem inteira, ás vezes sinuoso-serreada na metade anterior, face adaxial glabra, face abaxial glabra ou esparsamente serícea nas nervuras, nervuras laterais 8-12; pecíolo 0,5-2,0 cm compr., estreitamente aladorecurvado, glabro. Panícula 4,0-18,0 cm compr., glabra ou esparsamente pubescente. Sépalas glabras, com margem ciliada, externas $0,15-0,3 \mathrm{~cm}$ compr., circulares ou largamente ovais, internas 0,5-0,6(-0,8 após a antese) $\mathrm{cm}$ compr., largamente elípticas ou circulares, margens sobrepostas não formando alas; pétalas 5, 0,6-0,7 cm compr., obovais ou oblongas, glabras; estames 40-50, 3,0-4,0 mm compr., carpelo 1, glabro, ovário ca. 1,0 m compr., estilete ca. 3,0 mm compr. Cápsula 1, monosperma. Semente ca. 4,0 mm compr., oblata (achatada no ápice e na base).

Material examinado: Minas Gerais, Jaboticatubas, Serra do Cipó, caminho entre a rodovia MG-010 e a sede do IBAMA, 24.XI.2000, F.N. Costa et al. 234, fr. (SPF, SPFR). Santana do Riacho, Serra do Cipó, Rodovia MG-010, km. 95, estrada de terra em direção à Sede do IBAMA, $19^{\circ} 20^{\prime}$ S, $43^{\circ} 37^{\prime} \mathrm{W}$, 24.IX.2007, C.P. Bruniera et al. 78, fr. (CEPEC, ESA, K, RB, SPF, SPFR); idem, distrito de Cardeal Mota, sede da Fazenda Monjolos, 24-27.IX.2002, L.S. Kinoshita et al. 02/204, fr. (UEC); idem, Estrada Lagoa Santa - Conceição do Mato Dentro (ao longo do Rio Cipó), 1.VII.1981, A.M. Giulietti et al. s.n. CFSC 7364, fl. (SPF, SPFR). Santa Luzia, Serra do Cipó, 25.X.1961, A.P. Duarte 6391, fr. (RB).
Material adicional examinado: Minas Gerais, Grão-Mogol, Vale do Rio Itacambiruçu, $300 \mathrm{~m}$ a jusante da Foz do Córrego da Bonita, 16³5'48'S, 4254'36”'W, 5.XI.1987, R. Mello-Silva et al. CFCR 11602, fr. (SPF, SPFR).

Davilla nitida está distribuída pela América Central e América do Sul, até a Bolívia. No Brasil, está presente em matas de galeria no sul do Amazonas e em regiões de cerrado, com coletas em estados das Regiões Norte, Nordeste, Centro-Oeste e em Minas Gerais (Kubitzki 1971). Na Serra do Cipó a espécie ocorre nas bordas do cerrado, sendo que o material com flor foi coletado em julho e aqueles com frutos de setembro a novembro.

\section{Doliocarpus Rol.}

Lianas ou subarbustos. Inflorescência paniculada ou fasciculada com pedúnculos unifloros. Flores bissexuadas; sépalas 4-6, semelhantes entre si; pétalas 3-5, obovais; estames numerosos, persistentes no fruto; carpelo 1, unilocular, óvulos 2, estilete terminal, estigma peltado. Fruto baga capsular, deiscente na sutura, raramente indeiscente ou rompendo irregularmente; sementes 2 ou 1, arilo incluso completo.

O gênero Doliocarpus possui ca. 50 espécies descritas, com ampla distribuição na América Central e do Sul, desde o México até o sul do Brasil (Aymard 2007), sendo a Amazônia a região fitogeográfica com maior riqueza para o gênero (Fraga 2009). Na Serra do Cipó, ocorrem duas espécies.

Chave para as espécies

1. Lâmina foliar lanceoladas ou elípticas, face abaxial pubescente, com nervuras (central e laterais) proeminentes e seríceas. 3.1. D. dentatus

1'. Lâmina foliar oblanceoladas ou obovais, face abaxial glabra, nervura central serícea, as laterais não proeminentes, glabras a esparsamente pubescentes 3.2. D. elegans

3.1. Doliocarpus dentatus (Aubl.) Standl., J. Wash. Acad. Sci. 15: 286. 1925.

Fig. 2 H-K

Lianas ou arbustos escandentes; ramos jovens tomentosos, quando velhos glabros e acinzentados. Lâmina foliar 7,0-16,0 cm compr., 2,5-9,0 cm larg., cartácea a subcoriácea, lanceolada ou elíptica, ápice acuminado, base aguda ou obtusa, margem inteira ou levemente sinuosa, com a metade anterior serreado-denteada, quando jovens densamente seríceas em ambas as faces, quando velhas face abaxial pubescente, com nervuras (central e laterais) proeminentes e seríceas, face adaxial glabra, nervuras laterais 10-12; pecíolo $0,5-1,5 \mathrm{~cm}$ compr., canaliculado, seríceo a glabro. Fascículo 10-30 flores; pedúnculo 0,5-1,5 $\mathrm{cm}$ compr., unifloro, tomentoso, com bráctea basal. Sépalas 4-5, elípticas ou obovais, 3,0-5,0 mm compr., externamente tomentosa, internamente glabra; pétalas decíduas (não observadas); estames 40-50, 3,0-5,0 mm compr.; pistilo ca. $3,0 \mathrm{~mm}$ compr., glabro, ovário ca. $2,0 \mathrm{~mm}$ compr., estilete ca. 1,0 mm compr. Baga capsular globosa, 5,0-7,0 mm compr.; 5,0-7,0 mm diâm. Semente 1, ca. 5,0 mm compr., reniforme, arilo glutinoso.

Material examinado: Minas Gerais, Serra do Cipó, km 5 partindo da casa do IBAMA a Belo Horizonte, 20.IX.1994, J.A. Lombardi 624, fr. (BHCB); Estrada Serra do Cipó - Lagoa Santa, 24.VI.1993, J.A. Lombardi 292, fr. (BHCB). Jaboticatubas, Serra do Cipó, proximidades da Sede do IBAMA, 21.XI.2000, K. Yamamoto \& $S$.

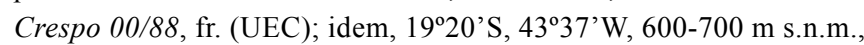
21.XI. 2000, L.S. Kinoshita \& M.E. Alencar 00/378, fr. (UEC). Santana do Riacho, UCAT, 24.II.1985, M.A. Lopes \& P.M. Andrade s.n., fr. (BHCB).

Material adicional examinado: Minas Gerais, Estação Ecológica UFMG, 27.VI.1990, E.M. Santos et al. 68, fl. (BHCB). São Paulo, Matão, 11.V.1949, J. Correa Gomes 268, bot. (RB, SPFR).

Doliocarpus dentatus possui distribuição neotropical, ocorrendo amplamente na América Central e do Sul, do México até o Paraguai e o sul do Brasil 
(Santa Catarina como limite meridional), possuindo uma ampla variação morfológica o que confere a este táxon sete subespécies (Kubitzki 1971), sendo D. dentatus subsp. dentatus a única subespécie presente na região sudeste do País e por conseguinte na Serra do Cipó. Além da variação morfológica presente na espécie, também é observada uma ampla variação nos ambientes ocupados por ela, ocorrendo mais freqüentemente em ambientes úmidos, em matas primárias e secundárias (Kubitzki 1971). No Brasil, ocorre também em matas de galeria e ocasionalmente no cerrado (Kubitzki 1971), sendo a maioria dos indivíduos da Serra do Cipó encontrados exatamente nestes ambientes (áreas de cerrado e de cursos d'água).

De acordo com as coletas é provável que a frutificação dessa subespécie ocorra durante o ano todo. Não foram coletados materiais com flores, sendo estas descritas com base em material adicional.

3.2. Doliocarpus elegans Eichler in Mart. \& Eichler, Fl. bras. 13(1): 76, t. 18, f. 1.1863.

Fig. $2 \mathrm{~L}-\mathrm{O}$

Lianas ou arbustos escandentes; ramos glabros, acinzentados ou amarronzados, descamantes. Folhas alterno-dísticas ou espiraladas, freqüentemente agrupadas nos ramos laterais; lâmina 3,0-13,0 cm compr., (1,2)1,5-4,5(4,8) cm larg., subcoriácea, oblanceolada ou oboval, raramente elíptica ou estreitamente elíptica, ápice obtuso, agudo, arredondado ou acuminado, base atenuada, margem inteira, às vezes denticulada na metade anterior da lâmina, face abaxial glabra, nervura central serícea, as laterais não proeminentes, glabras a esparsamente pubescentes, face adaxial glabra, nervuras laterais 7-12; pecíolo 0,3-0,8(-1,0) $\mathrm{cm}$ compr., glabro ou esparsamente pubescente. Fascículo 2-15 flores, pedúnculo 0,2-1,2 $\mathrm{cm}$ compr., indiviso ou ramificado em 2-4 flores, esparsamente pubescente, com bráctea presente na ramificação ou na base. Sépalas 4-5, elíptica ou obovais, 2,0-6,0 mm compr., glabras, ocasionalmente com tricomas esparsos na superfície externa; pétalas decíduas, geralmente 3 , obovais, 4,0-5,0 $\mathrm{mm}$ compr., glabras; estames $40-60$, ca. $6,0 \mathrm{~mm}$ compr.; pistilo ca. 3,0 mm compr., glabro, ovário ca. 1,0 mm compr., estilete ca. $2,0 \mathrm{~mm}$ compr. Baga capsular globosa, deiscência valvar, 4,0-8,0 mm compr., 5,0-7,0 cm diâm. Semente 1-2, ca. 5,0 $\mathrm{mm}$ compr., oboval, arilo glutinoso.

Material examinado: Minas Gerais, Conceição (do Mato Dentro), km 140, estrada de Conceição, 15.IV.1935, M. Barreto \& Brade 1292, fl. (BHCB); Conceição do Mato Dentro, Parque Natural Municipal do Ribeirão do Campo, 7.VII.2002, R.C. Mota et al. 1641, fr. (BHCB); idem, 1906'12,3"S, 4334'28,3"W, 19.III.2003, R.C. Mota e P. Viana 2079, fl. (BHCB). Congonhas do Norte, estrada para Santana do Riacho, Serra da Carapina (setor N da Serra do Cipó), 1856’S, $43^{\circ} 41^{\prime}$ W, 1200 m, 3.III.1998, J.R. Pirani et al. 4186, fl. fr. (SPF,
SPFR). Itambé do Mato Dentro, estrada para a Serra da Cabeça de Boi, após o Canta-Galo, 8.VIII.1992, J.R. Stehmann \& M.E. Sobral 1152, fr. (BHCB, UEC). Jaboticatubas, Serra do Cipó, Rodovia MG010, km 126, 3.IX.1973, J. Semir et al s.n. CFSC 4319, fr. (SP); idem, km 132, 28.V.1972, J. Semir et al. s.n. CFSC 2383, fl. (SP); idem, km 132, 16-24.II.1973, M. Sazima \& J. Semir s.n. CFSC 3916, fl. (SP). Santana do Riacho, Serra do Cipó, 24.IX.1993, J.A. Lombardi \& F.R.N. Toledo 432, fr. (BHCB); idem, Alto do Palácio, próximo a Estátua do Juquinha, 2.V.1993, V.C. Souza \& C.M. Sakuragui 3459, fl. fr. (ESA); idem, ao sul da Estátua do Velho Juca, 19¹5'49”S, 43³3'29,7'W, 1309 m s.n.m., 10.VI.2002, M. Groppo Jr. et al. 1095, fr. (SPF, SPFR); idem, APA Morro da Pedreira, Córrego Duas Pontes, 19¹7'27,1'S, 43³4'05”W, 1200 m s.n.m., 5.III.2002, J.R. Pirani et al. 5006, bot. (SPF, SPFR); idem, Rodovia MG-010, km 107, 04.VII.1978, A.M. Giulietti et al. s.n. CFSC 5453, fr. (SPF, SPFR); idem, km 110, 21.V.1989, J.R. Pirani et al. s.n. CFSC 11461, fl. fr. (SPF, SPFR); idem, km 111, Perto do Ribeirão Andrequecé, 22.VII.1980, N.L. de Menezes et al. s.n. CFSC 6367, fr. (SP); idem, km 114, 19.XII.1979, J.R. Pirani \& M.C. Amaral s.n. CFSC 5873, fr. (SP); idem, antigo km 115, 19¹7'33"S, 43³5'53"W, $1197 \mathrm{~m}$ s.n.m., 18.I.2004, J.R. Pirani et al. 5105, bot. (SPF, SPFR); idem, km 116, Córrego Duas Pontinhas, 1.IX.1986, D.C. Zappi \& C. Kameyama s.n. CFSC 9865, fr. (SPF, SPFR); idem, km 117, ca. 1200 m s.n.m., 25.IV.1978, G. Martinelli 4273, fr. (RB); idem, km 119, Córrego Três Pontinhas, 1290 m s.n.m., 28.IV.1990, A. Freire-Fierro 1588, fr. (SPF); idem, $19^{\circ} 16^{\prime} 05,2^{\prime \prime}$ S, 4332'48,8”W, 1229 m s.n.m., 16.VI.2007, C.P. Bruniera et al. 33 e 35, fr. (SPF, SPFR); idem, km 121, Estátua do Velho Juca, 19¹5'28,5”S, 4333’13,6”W, $1307 \mathrm{~m}$ s.n.m., 15.VI.2007, C.P. Bruniera et al. 28, fr. (K, RB, SPF, SPFR); idem, km 124, perto da Estátua do velho Juca, 2.V.1993, T.R.S. Silva \& J.R. Pirani s.n. CFSC 13099, fr. (SPF, SPFR); idem, km 126, Retiro Alto do Palácio, $1300 \mathrm{~m}$ s.n.m., 9.III.1990, A. Freire-Fierro et al. 1579 CFSC 11825, fr. (SPF, SPFR); idem, km 128, Alto do Palácio, 2.V.1986, K. Kubitzki \& J. Rohwer s.n. CFSC 9755, fr. (SPF); idem, km 132, 28.V.1972, J. Semir et al. s.n. CFSC 2342, fr. (SPF, SPFR); idem, ca. $9 \mathrm{~km}$ após Chapéu de Sol, 19¹7'25,5”S, 43³4’02,6”W, 1200 m s.n.m., 10.III.1995, V.C. Souza et al. 8183, fr. (SPF); idem, Estrada para a Usina Pacífico Mascarenhas, 19¹6'22,6”'S, 4336'09,9"W, 1005m s.n.m., 23.IX.2007, C.P. Bruniera et al. 68, fr. (ESA, K, RB, SPF, SPFR); idem, C.P. Bruniera et al. 70, fr. (CEPEC, ESA, RB, SPF, SPFR); idem, Estrada em direção à Cachoeira da Caverna, 19¹5'09,9"S, 4335'07,1”W, 1062m s.n.m., 23.IX.2007, C.P. Bruniera et al. 75, fr. (SPF, SPFR). Serra do Cipó, 26.II.1984, E. Costa 372, fl. (RB, SPFR); idem, ca. 1200 m, 20.II.1972, W.R. Anderson et al. 36355, fl. (RB); idem, antigo km 134, 14.II.1963, A.P. Duarte 7785 , bot. (RB, SPFR).

Doliocarpus elegans possui distribuição restrita ao Brasil, tendo sido coletada nos estados de Goiás e em Minas Gerais, ocorrendo em áreas de cerrado, principalmente em matas de galeria, até $1200 \mathrm{~m}$ altitude (Kubitzki 1971). Foi coletada na Serra do Cipó em matas de galeria, algumas vezes acima de $1200 \mathrm{~m}$ altitude. Os materiais com flores datam de janeiro a maio, e com frutos de março a setembro, com uma coleta em dezembro. 


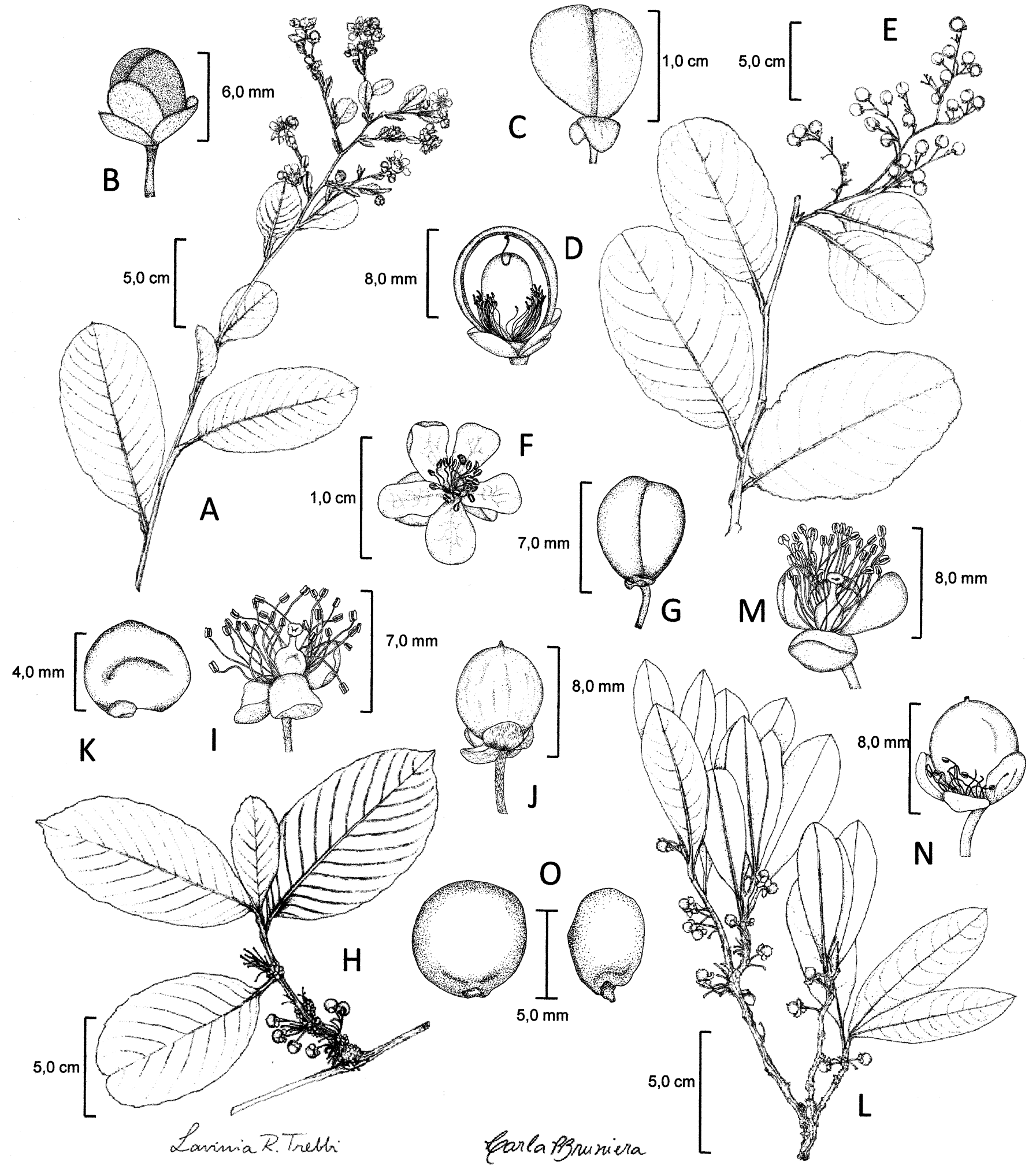

Fig. 2. A-D. Davilla grandiflora A.St.-Hil. \& Tul. A. Ramo com flores. B. Botão. C. Fruto envolvido pelas sépalas internas acrescentes. D. Fruto com uma das sépalas internas retirada. E-G. Davilla nitida (Vahl) Kubitzki. E. Ramo com frutos. F. Flor. G. Fruto envolvido pelas sépalas internas acrescentes. H-K. Doliocarpus dentatus Standl. H. Ramo com frutos. I. Flor com pétalas ausentes. J. Fruto. K. Semente em vista lateral, arilo retirado. L-O. Doliocarpus elegans Eichl. L. Ramo com frutos. M. Flor com pétalas ausentes. N. Fruto. O. Semente em vista lateral, à esquerda com arilo completo, à direita com arilo retirado. (A. Savassi-Coutinho et al. 937; B. Joly et al. CFSC 2552; C. Bruniera et al. 67; D. Bruniera et al. 72; E. Bruniera et al. 78; F. Giulietti et al. CFSC 7364; G. Mello-Silva et al. CFCR 11602; H. Santos et al. 31; I. Santos et al. 68; J, K. Kinoshita \& Alencar 00/378; L. Mota et al. 1641; M. Pirani et al. CFSC 11461; N. Silva \& Pirani CFSC 13099; O. Bruniera et al. 75) 


\section{Agradecimentos}

Os autores agradecem aos curadores dos herbários BHCB, ESA, RB, SP, SPF e UEC, pela disponibilização dos respectivos acervos para estudo e pelo empréstimo de materiais; ao Departamento de Biologia da FFCLRP, pela concessão do veículo para realização das coletas; à Lavínia Trebbi, pelos desenhos dos hábitos; à Tatiana Parreiras Martins, pela edição das imagens; a Cláudio Nicoletti Fraga e a um revisor anônimo pela leitura crítica do trabalho e importantes contribuições ao texto; à FAPESP e CNPq, pelo apoio financeiro concedido aos autores, e à Pró-Reitoria de Pesquisa da USP por parte do financiamento para as coletas.

\section{Referências}

AYMARD, G. 1997. Dilleniaceae Novae Neotropicae IX: Neodillenia, a new genus from the Amazon basin. Harvard Pap.Bot.10: 121-131.

AYMARD, G. 2007. Two new species of Doliocarpus (Dilleniaceae) from Colombia. Novon 17: 288-293.

EICHLER, A.G. 1863. Dilleniaceae. In C.P.F. Martius \& A.G. Eichler (eds) Flora brasiliensis. Frid. Fleischer. Leipzig, vol. 13(1), p. 65120, tab. 15-27.

FRAGA, C.N. \& AYMARD, G. 2007. Tetracera forzzae (Dilleniaceae), uma nova espécie para a Zona da Mata de Minas Gerais, Brasil. Novon 17: 433-436.

FRAGA, C.N. 2008. Three new species of Davilla (Dilleniaceae) from Bahia, Brazil. Brittonia 60(4): 355-361.
FRAGA, C.N. 2009. Dilleniaceae. In A.M. Giulietti, A. Rapini, M.J.G. Andrade, L.P. Queiroz \& M.J.C. Silva (orgs) Plantas raras do Brasil. Conservação Nacional. Belo Horizonte, p. 159-160.

GIULIETTI, A.M., MENEZES, N.L., PIRANI, J.R., MEGURO, M. \& WANDERLEY, M.G.L. 1987. Flora da Serra do Cipó, Minas Gerais: caracterização e lista das espécies. Bol. Bot. Univ. São Paulo 9: 1-151.

HORN, J.W. 2007. Dilleniaceae. In K. Kubitzki (ed.) The families and genera of vascular plants. Vol. 9: Flowering Plants, Eudicots. Springer-Verlag. Berlin-Heidelberg, p. 132-154.

HORN, J.W. 2009. Phylogenetics of Dilleniaceae using sequence data from four plastid loci (rbcL, infA, rps4, rpl16 INTRON). Int. J. Plant. Sci. 170(6): 794-813.

KUBITZKI, K. 1970. Die Gattung Tetracera (Dilleniaceae). Mitt. Bot. Staatssamml. München 9: 1-98.

KUBITZKI, K. 1971. Doliocarpus, Davilla und verwandte gattungen (Dilleniaceae). Mitt. Bot. Staatssamml. München 9: 1-105.

KUBITZKI, K. \& REITZ, P.R. 1971. Dileniáceas. In R. Reitz (ed.) Flora Ilustrada Catarinense. Herbário Barbosa Rodrigues. Itajaí.

KUBITZKI, K. 2004. Dilleniaceae. In N. Smith, S.A. Mori, A. Henderson, D.W. Stevenson \& S.V. Heald (eds.) Flowering plants of the Neotropics. The New York Botanical Garden. New York, p. 128-130.

MENDONÇA, F.B. \& SANO, P.T. 2003. Flora de Grão-Mogol, Minas Gerais: Dilleniaceae. Bol. Bot. Univ. São Paulo 21(1): 239-242.

ZMARZTY, S. 1995. Dilleniaceae. In B.L. Stannard (ed.) Flora of the Pico das Almas, Chapada Diamantina - Bahia, Brazil. Royal Botanic Gardens. Kew, p. 289. 